\title{
Stable silicon isotopes of groundwater, feldspars, and clay coatings in the Navajo Sandstone aquifer, Black Mesa, Arizona, USA
}

\author{
R.B. Georg ${ }^{\mathrm{a}, \mathrm{c}, *}$, C. Zhu $^{\text {b}}$, B.C. Reynolds ${ }^{\mathrm{c}}$, A.N. Halliday ${ }^{\mathrm{a}}$ \\ ${ }^{a}$ University of Oxford, Department of Earth Sciences, Parks Road, OX1 3PR Oxford, UK \\ ${ }^{\mathrm{b}}$ Indiana University, Department of Geological Sciences, USA \\ ${ }^{\mathrm{c}}$ ETH Zurich, Institute for Isotope Geochemistry \& Mineral Resources, Switzerland
}

Received 8 September 2008; accepted in revised form 3 February 2009; available online 14 February 2009

\begin{abstract}
We present some of the first analyses of the stable isotopic composition of dissolved silicon ( $\mathrm{Si}$ ) in groundwater. The groundwater samples were from the Navajo Sandstone aquifer at Black Mesa, Arizona, USA, and the Si isotope composition of detrital feldspars and secondary clay coatings in the aquifer were also analyzed. Silicon isotope compositions were measured using high-resolution multi-collector inductively coupled mass spectrometry (HR-MC-ICP-MS) (Nu1700 \& NuPlasma HR). The quartz dominated bulk rock and feldspar separates have similar $\delta^{30} \mathrm{Si}$ of $-0.09 \pm 0.04 \%$ and $-0.15 \pm 0.04 \%$ o $( \pm 95 \%$ SEM), respectively, and clay separates are isotopically lighter by up to $0.4 \%$ compared to the feldspars. From isotopic massbalance considerations, co-existing aqueous fluids should have $\delta^{30} \mathrm{Si}$ values heavier than the primary silicates. Positive $\delta^{30} \mathrm{Si}$ values were only found in the shallow aquifer, where $\mathrm{Si}$ isotopes are most likely fractionated during the dissolution of feldspars and subsequent formation of clay minerals. However, $\delta^{30} \mathrm{Si}$ decreases along the flow path from $0.56 \%$ to $-1.42 \%$, representing the most negative dissolved $\mathrm{Si}$ isotope composition so far found for natural waters. We speculate that the enrichment in ${ }^{28} \mathrm{Si}$ is due to dissolution of partly secondary clay minerals and low-temperature silcretes in the Navajo Sandstone. The discovery of the large range and systematic shifts of $\delta^{30} \mathrm{Si}$ values along a groundwater flow path illustrates the potential utility of stable Si isotopes for deciphering the Si cycling in sedimentary basins, tracing fluid flow, and evaluating global Si cycle.
\end{abstract}

(C) 2009 Elsevier Ltd. All rights reserved.

\section{INTRODUCTION}

Stable Si isotopes have been used to characterize and quantify terrestrial Si reservoirs since the 1950s (Reynolds and Verhoogen, 1953; Allenby, 1954), but were not very useful until the last two decades when there were significant advances in mass spectrometry. As shown below, there are a number of studies on stable silicon isotopes of rivers and oceans, but no studies of groundwater have been conducted. Groundwater is a major reservoir of fresh water

\footnotetext{
* Corresponding author.

E-mail address: Bastian.Georg@earth.ox.ac.uk (R.B. Georg).
}

on the earth, far larger than rivers and lakes (Schwartz and Zhang, 2002). Groundwater significantly contributes to streams, rivers, and lakes, and direct discharge into the oceans has been increasingly recognized as an important contribution of material fluxes to the oceans (Kim et al., 2005; Burnett et al., 2007; Niencheski, 2007; Moore et al., 2008).

It is established that igneous rocks have an average $\delta^{30} \mathrm{Si}$ value of $-0.3 \%$ (Douthitt, 1982; Ding, 1996; Ziegler et al., 2005a,b; Georg et al., 2007a,b). Clays, as the products of the chemical weathering of silicates, range in $\delta^{30} \mathrm{Si}$ between $-2.3 \%$ and $1.5 \%$, with the majority of clays being lighter than the average of igneous rocks (Douthitt, 1982; Ding, 1996; De La Rocha et al., 2000; Ziegler et al., 2005a,b). 
Biogenic silica spans the largest range of $\delta^{30} \mathrm{Si}$ observed in nature. Common to the formation of biogenic silica is the discrimination against heavy $\mathrm{Si}$ isotopes during Si utilization (De La Rocha et al., 1997; De La Rocha, 2003; Ding et al., 2005, 2008; Varela et al., 2004; Alleman et al., 2005; Cardinal et al., 2005; Opfergelt et al., 2006a,b).

The isotopic composition of dissolved $\mathrm{Si}$ in fresh water (lakes and rivers) and seawater shows enrichment in heavy $\mathrm{Si}$. The $\delta^{30} \mathrm{Si}$ of seawater ranges between $0.4 \%$ and $3.1 \%$ (De La Rocha et al., 2000; Varela et al., 2004; Cardinal et al., 2005; Reynolds et al., 2006; Beucher et al., 2008), and that of rivers between $0.4 \%$ and $3.4 \%$ (De La Rocha et al., 2000; Ding et al., 2004; Alleman et al., 2005; Ziegler et al., 2005a; Georg et al., 2006a, 2007b), although it should be stressed that values as high as $+3 \%$ appear to be exceptional.

The existing database of $\mathrm{Si}$ isotope compositions in natural systems is limited, but it shows that dissolved Si in surficial waters is isotopically heavy compared to igneous rocks, and secondary products, such as biogenic silica and clays, are generally isotopically light. Therefore, it is commonly believed that $\mathrm{Si}$ isotopes are fractionated during the weathering of silicate minerals/rocks and the release of Si into continental runoff. De la Rocha et al. (2000) concluded that riverine $\mathrm{Si}$ isotope compositions result from fractionation processes such as biological utilization of $\mathrm{Si}$ and the formation of clays.

In a recent contribution Basile-Doelsch et al. (2005) suggested that low-temperature silcretes, which formed in aquifers may represent a $\mathrm{Si}$ pool strongly depleted in heavy $\mathrm{Si}$ isotopes with $\delta^{30} \mathrm{Si}$ values as low as $-5.4 \%$. This then has the potential to counterbalance the positive shift of dissolved Si in surficial waters. However, the study by BasileDoelsch et al. (2005) focused on Cretaceous silcretes and did not provide analyses of $\mathrm{Si}$ dissolved in groundwater. Here we investigate the $\mathrm{Si}$ isotope composition of dissolved $\mathrm{Si}$ in the Navajo Sandstone aquifer, Black Mesa, Arizona and compare it to the $\mathrm{Si}$ isotope compositions of the feldspar and quartz grains and clay coatings in the aquifer. This study is an extension of a paper presented at the AGU fall meeting in 2005 (Georg et al., 2005), which together with Ziegler et al. (2005a) represents the first isotope data for dissolved $\mathrm{Si}$ in groundwater in silicate rock aquifers.

\section{GEOLOGY, HYDROGEOLOGY, AND MINERALOGY}

The Navajo Sandstone aquifer in the Black Mesa basin, Arizona (Fig. 2a), is a $14,000 \mathrm{~km}^{2}$ regional aquifer and the most important source of potable water for the region (Cooley et al., 1969; Eychaner, 1983; Zhu, 2000). The most productive unit in the Navajo Sandstone aquifer is the Navajo Sandstone, a Jurassic eolian quartz sandstone well known for its large cross bedding and spectacular landforms. Groundwater in the Navajo Sandstone aquifer moves southeast from the Shonto area toward the center of the mesa, where the flow path diverges northeastward toward Laguna Creek and Chinle Wash and southwestward toward Moenkopi Wash (Cooley et al., 1969; Brown and Eychaner, 1988). The aquifer is recharged seasonally from precipitation in the highlands, principally during the winter and spring. The Shonto area, in the northwestern corner of the mesa, accounts for approximately one-third of the total recharge in the basin and most of the water that flows into the center of the basin (Cooley et al., 1969). The principal discharge areas are along the Moenkopi Wash near Tuba City.

The Navajo Sandstone (N) aquifer is overlain unconformably by the silty Carmel Formation, which hydraulically separates the $\mathrm{N}$ and $\mathrm{D}$ aquifers in the Black Mesa area (Fig. 2). The groundwater from the $\mathrm{D}$ aquifer is characterized by elevated $\mathrm{SO}_{4}^{2-}, \mathrm{Cl}^{-}$, and $\mathrm{Na}^{+}$concentrations and high total dissolved solids (TDS between 124 and $290 \mathrm{mg} \mathrm{L}^{-1}$ for the samples analyzed herein). Leaking of $\mathrm{D}$ water into the Navajo Sandstone aquifer is restricted to the southeast edges of the mesa.

The current climate in the Black Mesa area is semiarid, with a mean annual precipitation of $300 \mathrm{~mm}$, but as much as $420 \mathrm{~mm}$ in areas above $1800 \mathrm{~m}$ in elevation. The mean annual temperature is about $10{ }^{\circ} \mathrm{C}$ in the Shonto area. Vegetation consists of grass shrubs at altitudes below $1670 \mathrm{~m}$, pinion-juniper between 1670 and $2280 \mathrm{~m}$, and pine forest above $2280 \mathrm{~m}$ (Cooley et al., 1969).

\section{SAMPLING AND ANALYTICAL METHODS}

\subsection{Sampling and analyzing groundwater}

Six groundwater samples along a flow path of $100 \mathrm{~km}$, were collected from municipal and production wells that are screened in the Navajo Sandstone aquifer at Black Meza, Arizona, USA. Prior to sample collection, sample bottles were soaked in $0.5 \mathrm{~N} \mathrm{HCl}$ overnight, and then rinsed with ultra pure $\mathrm{HCl}$ and ultrapure de-ionized water. In the field, the wells had been pumped for sufficient time for well purging. Temperature, electric conductivity, $\mathrm{pH}$, and dissolved oxygen were continuously monitored, and samples were taken after steady reading was reached. A braided plastic tube was connected to the spigot of the well with a garden hose connector, and the filter was attached to the other end of the tube. The tube was rinsed for about $10 \mathrm{~min}$ before sampling. The bottles were rinsed three times with sampling water before being filled. Samples were filtered through $0.2 \mu \mathrm{m}$ polysophone filter (Pall 12122). For comparison, a second set of duplicate samples were collected and analyzed with Gelman $0.45 \mu \mathrm{m}$ capsule filters. All samples were acidified to $\mathrm{pH} 2$ with VWR ultrex II $\mathrm{HCl}$ regent (with $100 \mathrm{ppt}$ specification or $<20 \mathrm{ppt}$ in assay). One blank sample was prepared in the field with ultrapure de-ionized water. Samples for anion analyses were placed on ice immediately and kept cool until analyses.

For cation concentrations, samples were analyzed on a ThermoElemental PQ ExCell argon ICP quadrupole mass spectrometer with a simultaneous analog and pulse counting detector (courtesy of University of Minnesota). All blanks, standards, and samples are acid matrix matched to lessen matrix and polyatomic overlap effects and are diluted such that element concentrations are in the linear working range of the standard and detector combination. Groundwater samples were also collected for ion chromatographic analysis of anion concentrations $\left(\mathrm{F}^{-}, \mathrm{Cl}^{-}, \mathrm{Br}^{-}\right.$, 
$\mathrm{SO}_{4}^{2-}, \mathrm{NO}_{3}^{-}, \mathrm{NO}_{2}^{-}$, and $\mathrm{PO}_{4}^{3-}$, employing a Dionex $\mathrm{IC} 25$ Ion chromatograph at Indiana University, Bloomington.

\subsection{Solid sampling and size fractionation}

The solid material analyzed for this study stem from drill cores for hydrocarbon exploration wells (Zhu et al., 2006). The clay fraction was removed as follows. The crushed rock samples were added to a beaker containing de-ionized water and the mixture placed in an ultrasonic bath. After $10 \mathrm{~min}$, the supernatant and suspension were decanted into $200 \mathrm{ml}$ centrifuge bottles and capped. The beaker was then refilled with $50 \mathrm{ml}$ of de-ionized water and sonicated for another $10 \mathrm{~min}$. Supernatants were centrifuged at 3600 RPM for $60 \mathrm{~min}$, or until clear. The clear liquid of the centrifuged sample was decanted, and the clay-rich fraction was vacuum filtered with a Millipore type VCTP $0.1 \mu \mathrm{m}$ filter, collected and dried for further processing. The clay fractions collected in this way are mainly smectite with trace kaolinite (Zhu et al., 2006).

For the feldspar analyses the rock sample was gently crushed using a boron-carbide mortar and pestle, and subsequently washed in warm $\left(60^{\circ} \mathrm{C}\right) 2 \mathrm{M} \mathrm{HCl}$ until grains turned from a reddish patina to ivory white, documenting the removal of $\mathrm{Fe}$ coatings. Sixty-six feldspar grains were hand picked under a binocular microscope. Notwithstanding the careful separation based on cleavage of crystal faces, it is not totally certain that no quartz grain was included among this "feldspar fraction".

\subsection{Silicon isotope determination - mass spectrometry}

Silicon isotope compositions of the silicate mineral phases were analyzed at ETH Zurich in 2005, using the Nu1700 high-resolution multi-collector inductively coupled plasma mass spectrometer (HR-MC-ICP-MS), following the procedure described in more detail elsewhere (Georg et al., 2006b). Groundwater samples were analyzed using a high-resolution MC-ICP-MS (NuPlasma HR) in the Department of Earth Sciences, University of Oxford, in early 2007. This type of mass spectrometer is capable of high mass resolution, and therefore enables the interference-free determination of all three stable $\mathrm{Si}$ isotopes in pseudo high-resolution mode. The instrumental mass bias was corrected by a standard-sample bracketing protocol. Samples were taken up via a self-aspirating $6 \mathrm{~mm}$ concentric micro-flow PFA nebuliser with typical uptake rates around $80 \mu 1 \mathrm{~min}^{-1}$ and aspirated into a DSN-100 (Nu Instruments) desolvation device. The dried sample aerosol is introduced into the plasma using a semi-demountable torch equipped with a sapphire injector (Elemental Scientific Inc.). The base sensitivity (low resolution mode) of the MC-ICP-MS is typically $6-7 \times 10^{-10} \mathrm{~A} \mathrm{ppm}^{-1} \mathrm{Si}$, with an uptake rate of $0.1 \mathrm{ml} \mathrm{min}^{-1}$. However, setting the mass spectrometer to medium resolution mode (changing source slit width from 0.3 to $0.05 \mathrm{~mm}$ ) reduces the transmission by approximately $80 \%$. Further reduction is given by narrowing the alpha slits located in front of the electrostatic analyzer to correct for further beam aberrations. The overall loss in transmission is around $90 \%$ and was compensated by higher concentrations of $\sim 1.5 \mathrm{ppm} \mathrm{Si}$, resulting in 7 $10 \times 10^{-11} \mathrm{~A}$ total beam intensities on Faraday cups containing $10^{11} \Omega$ resistors. Each sample was analyzed at least 11 times, where each single $\delta$-value represents one sample run and two bracketed standard runs. One run consists of 25 cycles, each integrated for $8 \mathrm{~s}$. The signal to background ratio is typically on the order of 400 and the baseline is estimated from deflecting the beam for $30 \mathrm{~s}$ with the electrostatic analyzer. Silicon isotope data are reported as deviations of ${ }^{30} \mathrm{Si} /{ }^{28} \mathrm{Si}$ and ${ }^{29} \mathrm{Si} /{ }^{28} \mathrm{Si}$ from the international standard NBS-28 in parts per thousand (the standard delta notation $\delta^{30} \mathrm{Si}$ and $\delta^{29} \mathrm{Si}$, with $\mathrm{R}={ }^{30} \mathrm{Si} /{ }^{28} \mathrm{Si}$ or ${ }^{29} \mathrm{Si} /{ }^{28} \mathrm{Si}$ ) as follows:

$\delta^{30,29} \mathrm{Si}=\left[\left(\frac{R_{\text {Sample }}}{R_{\mathrm{NBS}-28}}\right)-1\right] \times 1000$

Measurement accuracy was checked using various calibrated $\mathrm{Si}$ isotope standards, such as IRMM-018, Diatomite and BigBatch. The reproducibility of IRMM-018 for a period of 6 months is $\pm 0.15 \%$ o $\delta^{30} \mathrm{Si}$ and $\pm 0.08 \%{ }^{29} \mathrm{Si}\left( \pm 2 \sigma_{\mathrm{SD}}\right.$, $n=95$ ). The accuracy of IRMM-018 is given with $\delta^{30} \mathrm{Si}$ of $-1.63 \pm 0.15 \%$ and $\delta^{29} \mathrm{Si}$ of $-0.84 \pm 0.08 \%$ is in agreement with the "calibrated" values for IRMM-018 with $\delta^{30} \mathrm{Si}$ of $-1.65 \pm 0.22 \%$ and $\delta^{29} \mathrm{Si}-0.85 \pm 0.14 \%$ (Reynolds et al., 2007). Likewise, IRMM-018, silicon isotope values for BigBatch, Diatomite and BHVO-1 show consistency with calibrated values (Abraham et al., 2008), data are given in Table 1 .

\section{RESULTS}

The isotope data are given in Table 1 and as a 3-isotope plot in Fig. 3. It is important to note that the water samples using $0.2 \mu \mathrm{m}$ and $0.45 \mu \mathrm{m}$ pore size filters show negligible differences in $\mathrm{SiO}_{2}(\mathrm{aq})$ and $\mathrm{Al}^{3+}$ concentrations. This indicates that groundwater samples from the Navajo Sandstone do not contain significant amounts of colloidal aluminosilicate in the range of 0.2 and $0.45 \mu \mathrm{m}$, and that the analyzed silicon isotope composition represents the dissolved silica.

The bulk quartz sample and the separated feldspar fraction yield isotope data of $\delta^{30} \mathrm{Si}-0.09 \pm 0.04 \%$ and $-0.15 \pm 0.04 \%$ o $(95 \% \mathrm{SEM})$, respectively. The clays yield $\delta^{30} \mathrm{Si}$ data of $-0.24 \pm 0.05 \%,-0.16 \pm 0.04 \%, \quad-0.30 \pm$ $0.04 \%,-0.42 \pm 0.04 \%$ and $-0.52 \pm 0.04 \%$ ( $95 \%$ SEM), respectively. The analyses of the Navajo Sandstone feldspars and five co-existing clay mineral samples show that the majority of the clay separates is isotopically lighter by up to $0.4 \%$ than the feldspar minerals. Isotopic variations of Si among primary silicate minerals of the same provenance are usually quite small and barely resolvable with current techniques (Georg, 2006). The Navajo Sandstone is a highly sorted eolian sedimentary rock and its sedimentary as well as petrographic composition is homogenous across the scale considered here. Given the expected small variability of $\mathrm{Si}$ isotope composition and the homogeneity of the rock, we can consider the results for the quartz and feldspars to be representative.

Dissolved $\mathrm{Si}$ in the groundwater samples shows a wider range of $\delta^{30} \mathrm{Si}$ values $( \pm 95 \% \mathrm{SEM})$, ranging from $0.56 \pm$ $0.04 \%$ and $0.42 \pm 0.04 \%$ (Shonto PM2 and PM4), evolving 
Table 1

Silicon isotope data of standards, silicates and water samples.

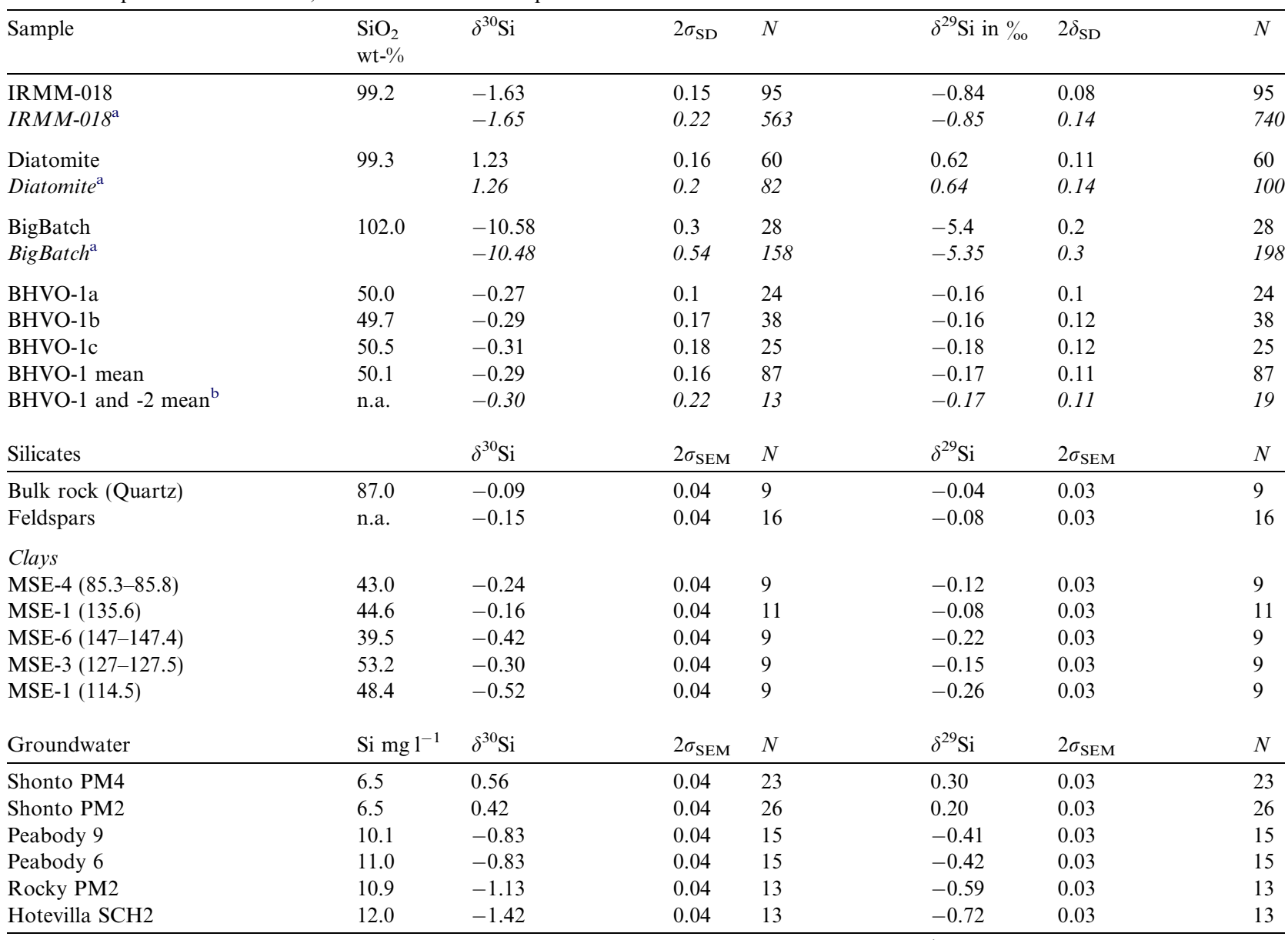

Silicon isotope data, wt- $\%$ and concentration of analyzed samples and standards. Uncertainties for $\delta^{30 / 29} \mathrm{Si}$ of standards are given as $\pm 2 \sigma_{\mathrm{SD}}$ in $\%$, and as $\pm 2 \sigma_{\mathrm{SEM}}$ for water and silicate samples.

n.a. = not available

a "Calibrated" Si isotope values, Reynolds et al., 2007.

b Data for BHVO-1 and -2 from Abraham et al. (2008).

towards negative values of $-0.83 \pm 0.04 \%$ (NAV9 and NAV6), $-1.13 \pm 0.04 \%$ (Rocky Ridge PM2) and eventually $-1.42 \pm 0.04 \%$ o (Hotevilla $\mathrm{SCH} 2$ ) with increasing flow distance and travel time $(\sim 35 \mathrm{kyr}$ at Hotevilla $\mathrm{SCH} 2-$ ${ }^{14} \mathrm{C}$ age data from Zhu (2000)) (Fig. 2b). The concentration of dissolved $\mathrm{Si}$ is $\sim 7 \mathrm{mg} \mathrm{l}^{-1}$ in shallow groundwater and between 10 and $12 \mathrm{mg}^{-1}$ in deep groundwater, but no correlation is found between $\mathrm{Si}$ concentrations and isotope compositions. The $\mathrm{Si}$ isotope composition of the older and deeper groundwater is clearly distinct from the typical positive $\mathrm{Si}$ isotope composition usually found in surficial waters, e.g. rivers, lakes and oceans or in pore waters of weathering profiles (Fig. 1).

\section{DISCUSSION}

\subsection{Clay precipitation induced $\mathrm{Si}$ isotope fractionation}

The eolian Jurassic Navajo Sandstone is composed of about $92 \%$ quartz and $\sim 4 \% \mathrm{~K}$-feldspar, with the remainder being calcite, plagioclase, $\mathrm{Fe}-\mathrm{Ti}$ oxides, hematite, tourma- line, zircon, apatite, barite, smectite and kaolinite (Harshbarger et al., 1957; Dulaney, 1989; Zhu, 2005; Zhu et al., 2006). The K-feldspar grains are covered with kaolinite, and both kaolinite and feldspars are covered with a mantle of smectite (Zhu et al., 2006). Petrographic studies demonstrated that the clay minerals were formed in situ as alteration of feldspar, and the smectite is of a low-temperature variety (Zhu, 2005; Zhu et al., 2006). The K-feldspar isotopic composition of $-0.15 \%$ is quite close to the composition of the quartz. The clays show lighter $\mathrm{Si}$ isotope compositions when compared to the feldspar, demonstrating a fractionation between co-existing primary and secondary minerals (Fig. 3). However, the magnitude of fractionation is not large $\left(\max \Delta_{\text {fsp-clay }}:-0.4 \%\right.$ ). For comparison, Ziegler et al. (2005b) found kaolinite as much as $2 \%$ lighter compared to primary biotite and plagioclase in a granitic saprolite in Puerto Rico. One reason for the smaller fractionation found here, could be the composition of the clay fraction, which in our samples consists mostly of smectite with minor amount of kaolinite. The lower overall fractionation between clays and primary minerals could 


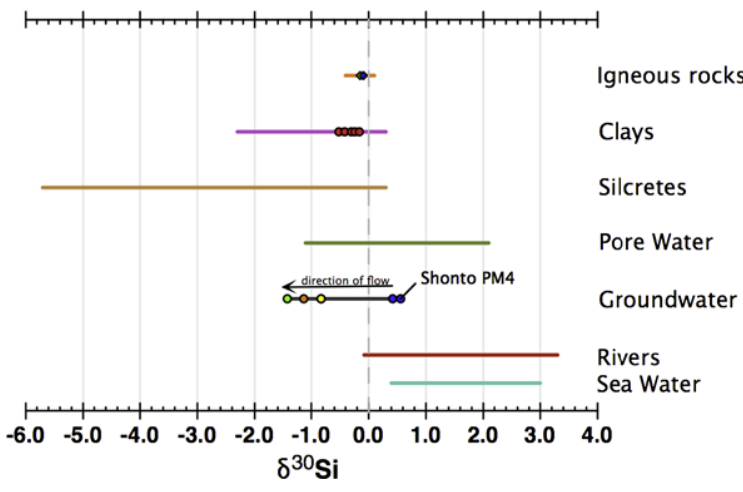

Fig. 1. Main isotope composition of major terrestrial Si pools, lines represent compiled literature data, data from this study are indicated for groundwater, clays and igneous materials; Seawater: Cardinal et al. (2005), De La Rocha et al. (2000), Reynolds et al. (2006) and Varela et al. (2004), Rivers: Alleman et al. (2005); De La Rocha et al. (2000); Ding et al. (2004); Georg et al. (2006a, 2007); Ziegler et al. (2005a), Groundwater: this study, Pore water: Ziegler et al., 2005a,b Silcretes: Basile-Doelsch et al., 2005, Clays: this study, De La Rocha et al., 2000; Ding, 1996; Douthitt, 1982; Ziegler et al., 2005a,b, Igneous materials: this study, Ding, 1996; Douthitt, 1982; Ziegler et al., 2005a,b.

mean that smectite is in general less fractionated than kaolinite. However, the cause of fractionation between smectite, kaolinite, and feldspar is unknown and requires further investigation.

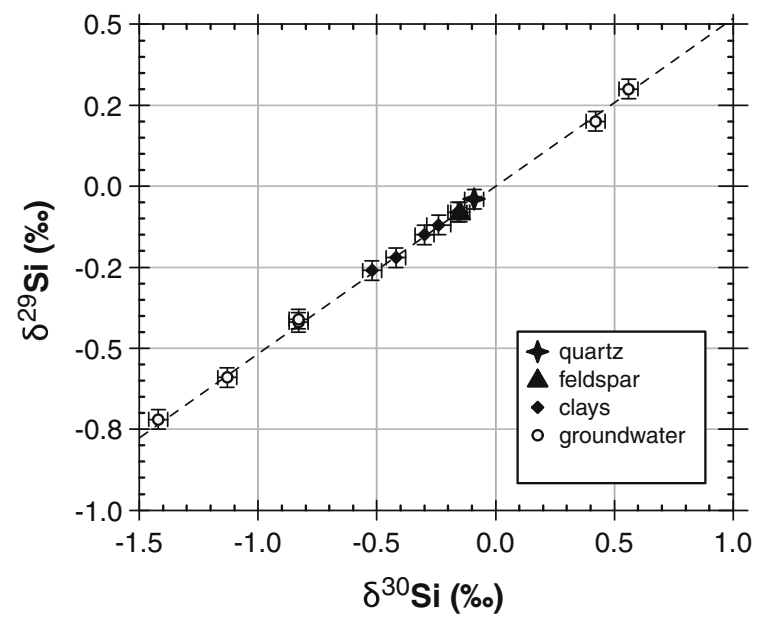

Fig. 3. Silicon isotope data for silicates and water samples all plot onto a single mass dependent fractionation line with a slope of $0.5178 x$, indicating the complete resolution from interfering species. Errors are $\pm 95 \%$ SEM.

Saturation indices calculations (Appendix A) show that kaolinite is supersaturated in groundwater from wells Shonto PM2 and PM4. Feldspars are either undersaturated or close to saturation within Shonto PM2 and PM4. From recharge water (mostly snow melt) to the shallow groundwater in this area, significant amount of dissolved constituents were acquired by groundwater, which indicate active
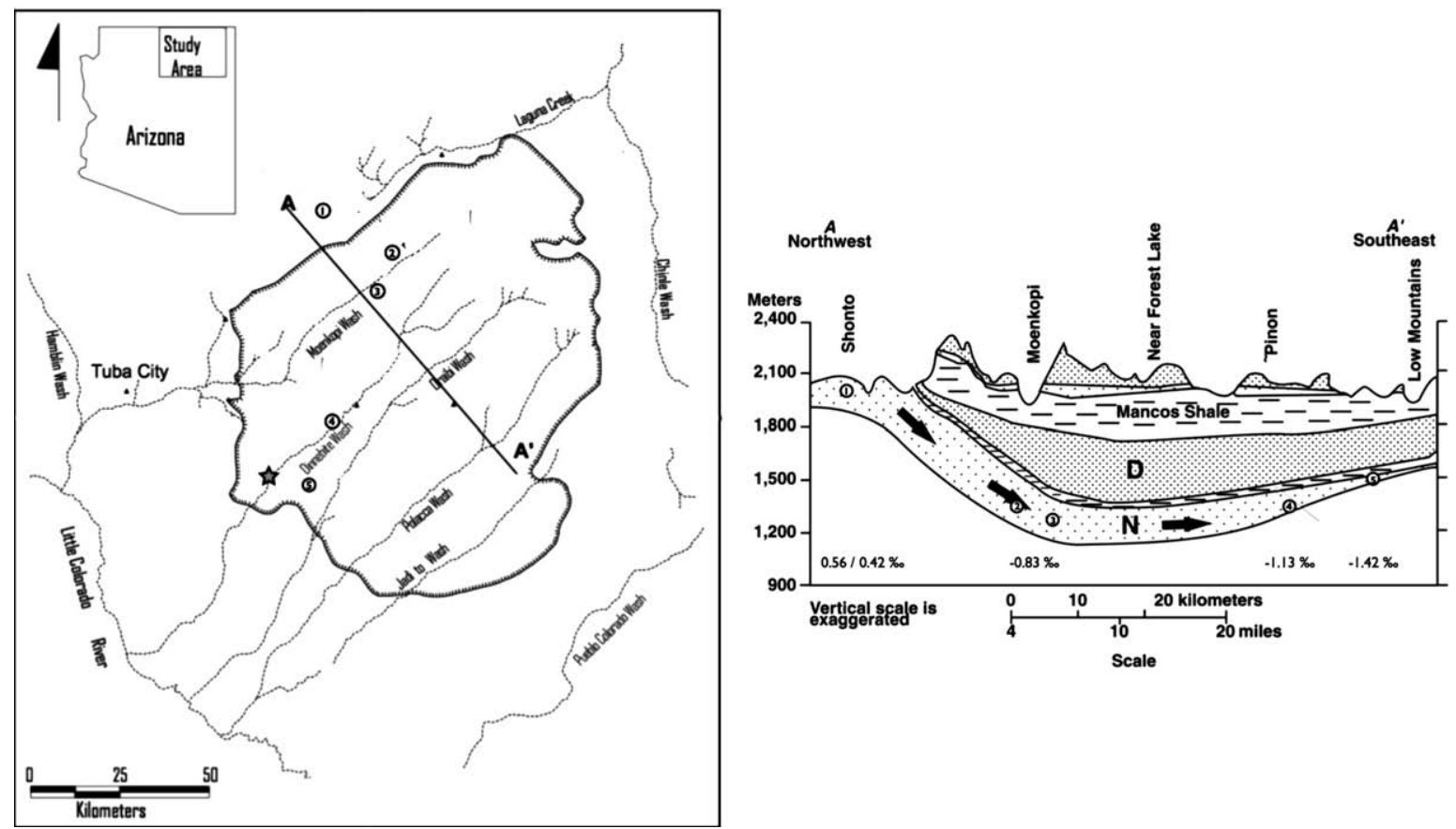

Fig. 2. (a) Groundwater sample locations and map of the study area. The cross-section along the profile A-A' is shown in (b). Well locations are 1: Shonto PM2 and PM4, 2: Nav9, 3: Nav6, 4: Rocky Ridge PM2, 5: Hotevilla SCH2, star denotes sampling location of silicate samples. The location map is a courtesy of Margoit Truini of USGS. (b) Profile (A- $\mathrm{A}^{\prime}$ in Fig. 1) through the N-aquifer that shows the approximate aquifer depths. The numerical values are $\delta^{30} \mathrm{Si}$ values of groundwater samples taken from the respective wells. The map is a courtesy of Margoit Truini of USGS. 
dissolution of feldspar among other reactions (Zhu, 2000). The groundwater samples from PM2 and PM4 have $\delta^{30} \mathrm{Si}$ compositions of $0.42 \%$ and $0.56 \%$, respectively. Hence, it appears that the $\delta^{30} \mathrm{Si}$ data at Black Mesa are consistent with other studies of weathering systems (Ziegler et al., $2005 a, b)$. Feldspars alter into more stable secondary phases and cause $\mathrm{Si}$ isotope fractionation with positive $\delta^{30} \mathrm{Si}$ dissolving in groundwater and isotopically light $\mathrm{Si}$ being incorporated into clays.

The isotope dataset for primary, secondary silicates and dissolved $\mathrm{Si}$ in groundwater provides evidence in support of the prevailing theory of $\mathrm{Si}$ isotope fractionation during clay formation (De La Rocha et al., 2000; Ziegler et al., 2005a,b; Georg et al.,2006a,b). However, it should be noted that the groundwater and clay coatings could represent products of different time scales. The Navajo Sandstone has gone through many overprinting events in its 200 million years history and these overprinting events are difficult to distinguish (Zhu et al., 2006). Additionally, there are references in the literature, which suggest that the coating clays are derived from infiltration of detrital clays in the vadose zone (Matlack et al., 1989; Mucke, 1994). However, the latest petrographic studies show that the clay coatings do not only cover the outer K-feldspar mineral surfaces, but they also occur in fissures and crevices along cleavages and within the interior of grains, representing a weathering front (Zhu, 2005; Zhu et al., 2006) and supporting the idea of in-situ formation.

If clay formation occurred earlier in the geological history of the Navajo Sandstone, other processes must explain the observed positive Si isotope composition of groundwater from Shonto PM2 and PM4. The Navajo Sandstone contains hematite as Fe-oxide coatings, a common feature giving the rock its red color (Dulaney, 1989). Iron-oxides exhibit the potential for $\mathrm{Si}$ isotope fractionation during $\mathrm{Si}$ adsorption, where light $\mathrm{Si}$ isotopes are preferentially adsorbed onto Fe-oxide mineral surfaces (Delstanche et al., 2009). Therefore, the adsorption of $\mathrm{Si}$ onto Fe-oxides provides a mechanism that could explain the positive $\mathrm{Si}$ isotope composition observed in some of the groundwater samples.

In either case, the positive $\mathrm{Si}$ isotope composition found in groundwater from Shonto PM2 and PM4 is different from the negative $\mathrm{Si}$ isotope composition found deeper in the $\mathrm{N}$-aquifer. The $\mathrm{Si}$ isotope composition evolves from positive to negative values, which can be explained by neither clay formation nor adsorption of $\mathrm{Si}$ on Fe-oxides.

\subsection{Silicon isotopic evolution of groundwater}

If the clay and/or adsorption on Fe-oxides were the only reactions that affect the silicon isotope composition in the $\mathrm{N}$ aquifer, there should be an increase of $\delta^{30} \mathrm{Si}$ values along the $100 \mathrm{~km}$ flow path. In contrast, $\delta^{30} \mathrm{Si}$ decreases by $2 \%$ and reaches values more negative than any sources identified in the solid phases. This requires either a source of isotopically light $\mathrm{Si}$ or a sink for heavier $\mathrm{Si}$ isotopes. However, a sink for heavier $\mathrm{Si}$ isotopes has not been recognized, and processes involving inorganic phases, e.g. dissolution-precipitation cycles and adsorption of $\mathrm{Si}$, prefer light $\mathrm{Si}$ isotopes over heavy, creating a sink for light $\mathrm{Si}$ isotopes and enrichment of heavier
$\mathrm{Si}$ isotope in the residual phase (Basile-Doelsch et al., 2005; Ziegler et al., 2005a; Delstanche et al., 2009).

The groundwater encounters an increase in temperature from 14 to $35^{\circ} \mathrm{C}$ and an increase of $\mathrm{pH}$ from 7.6 to 9.0 as the aquifer dips down to $\sim 1.58 \mathrm{~km}$ depth flow path from the wells in the Shonto recharge area towards the Peabody wells (NAV6 and NAV9). The groundwater shows concomitant changes in water chemistry, with dissolved Si increasing from $\sim 6$ to $10-11 \mathrm{mg} / \mathrm{L}$ and dissolved $\mathrm{Al}$ from 0.2 to $9.6 \mu \mathrm{g} / \mathrm{L}$ (Fig. A1), and decrease in $\delta^{30} \mathrm{Si}$ of $1.2 \%$. The steep increase in $\mathrm{Si}$ concentration rather requires a source, enriched in ${ }^{28} \mathrm{Si}$, than a sink for heavier $\mathrm{Si}$ isotopes, in order to explain the decrease towards negative $\delta^{30} \mathrm{Si}$ values. Saturation index calculations show that groundwater becomes undersaturated with respect to kaolinite downstream from the Shonto wells, which means that this phase is not stable and might dissolve if present. The saturation state of the groundwater with respect to smectite evolves from undersaturated closer to saturation, indicating that the dissolution of smectite takes place and actually contributes to the dissolved load. The shifts in saturation with respect to secondary minerals suggest that dissolution of clay coatings occurs in the deeper part of the aquifer, and can account for the increase in dissolved $\mathrm{Si}$ and $\mathrm{Al}$, as well as enrichment in lighter $\mathrm{Si}$ isotopes, thus the source for dissolved $\mathrm{Si}$ appears to have changed from primary mineral dissolution to secondary mineral dissolution. A comparable switch, from primary $\mathrm{Si}$ to secondary $\mathrm{Si}$ sources, has been observed in basaltic weathering chronosequences from Hawaii (Ziegler et al., 2005a), where secondary minerals become the main $\mathrm{Si}$ source for isotopically negative $\mathrm{Si}$ in pore waters within the older soil sequences. However, as pointed out in Section 5.1 , the observed isotope composition of the different clay samples is not sufficiently negative to directly explain the lightest $\delta^{30} \mathrm{Si}$ values in these groundwater samples. The increase in $\mathrm{Al}$ concentration is not sufficiently pronounced to explain the larger increase in Si concentration with clay dissolution alone. Therefore, the increase in Si concentration points towards another $\mathrm{Si}$ source, which typically would be enriched in lighter $\mathrm{Si}$ isotopes.

The solubility of silica increases sharply with increasing $\mathrm{pH}$ from the neutral to alkaline range, likewise with increasing temperature (Appendix A). A potential source for isotopically light $\mathrm{Si}$ could be low-temperature silcretes, precipitated form $\mathrm{Si}$ rich fluids. Basile-Doelsch et al. (2005) found Cretaceous low-temperature silcretes with average $\delta^{30} \mathrm{Si}$ values as negative as $-5.7 \%$ in sandstone from southern France. The Navajo Sandstone was cemented by quartz and chert cements during early digenesis and silcretes are a common component of the Navajo Sandstone (Bromley, 1992). Geochemical modeling shows that the groundwater analyzed herein is supersaturated with respect to quartz but undersaturated with respect to amorphous silica. Water from the Shonto wells is slightly supersaturated with respect to chalcedony, but samples downstream from Shonto are slightly undersaturated (Appendix A). If the silcretes from the Navajo Sandstone have crystallinity between detrital quartz and amorphous silica or solubility similar to chalcedony, dissolution of silcretes would take place in some segments of the flow path. 
We neither have silcrete samples from the Navajo Aquifer nor the in-situ techniques required to commence $\mathrm{Si}$ isotope analyses of silcretes, and the following discussion thus remains speculative. Silcretes are an abundant feature in these rocks and the changes in water chemistry would favor their dissolution, hence the shift in Si concentration would coincide with changes in water chemistry. By analogy with the silcretes analyzed by Basile-Doelsch et al. (2005), it is reasonable to assume that silcretes in the Navajo Sandstone are isotopically negative; hence they inhibit a source of $\mathrm{Si}$ enriched in lighter $\mathrm{Si}$ isotopes and could well explain the $1.2 \%$ decrease from Shonto to Peabody wells (NAV6 and NAV9). A mean $\delta^{30} \mathrm{Si}$ value of $-3 \%$ would suffice to lower the $\delta^{30} \mathrm{Si}$ by about $1.2 \%$ from $0.5 \%$ (mean $\delta^{30} \mathrm{Si}$ value from Shonto PM2 and PM4) to values of $-0.83 \%$ (NAV6 and NAV9), taking the associated increase in $\mathrm{Si}$ concentration of $38 \%$ along the flow path from Shonto to Peabody wells into account. A $\delta^{30} \mathrm{Si}$ value of $-3 \%$ for silcretes is well within the range observed for quartz cement in similar settings (Basile-Doelsch et al., 2005).

Further downstream from the Peabody wells to Hotevilla $\mathrm{SCH} 2, \delta^{30} \mathrm{Si}$ decreases from $-0.83 \%$ to $-1.42 \%$, but the dissolved silica contents do not increase significantly (see Figs. A1 and A4). The enrichment of lighter dissolved Si isotopes of groundwater may result from the dissolution of isotopically lighter silcretes, where the fluids reflect the isotopic composition of the solid phase. This would imply that the silcretes show progressively lighter $\mathrm{Si}$ isotope compositions along the groundwater flow path. Basile-Doelsch et al. (2005) suggested a model based on fluctuating groundwater tables in order to explain the isotopic composition of different silcrete generations within the aquifer. Silicification of the Navajo Sandstone took place early in diagenetic history, when fluctuating groundwater tables caused intermittent injection of alkaline fluids into sand deposits (Bromley, 1992). Large amounts of Si were mobilized during repeating wet-dry cycles and silcretes were precipitated in the pore space of the vadose zone. The water table in this shallow perched aquifer was inclined towards the effluence, and as a result, the water flowed laterally mobilizing material in this direction. The cementation front was likewise moving laterally and fresh silcretes were precipitated with Si dissolved from material 'older' than the active cementation front (Bromley, 1992). The $\mathrm{Si}$ isotope composition of the recent groundwater, assumed to be in equilibrium with the silcretes, might contain information about the palaeo-direction of those fluids that caused the silicification. Repeated wet-dry periods would transport Si by re-dissolution and re-precipitation. Different generations of silcretes show progressing lighter Si isotope compositions (Basile-Doelsch et al., 2005). For a sandstone formation, such as the Navajo Sandstone, this could result in a scenario, in which the silcrete generations become enriched in light $\mathrm{Si}$ isotopes with progressing cementation front, and the evolution of $\mathrm{Si}$ isotopes in silcretes towards lighter isotope compositions would coincide approximately with the flow direction of the formation fluid from which those silcretes were precipitated. The isotope evolution of the recent groundwater shows progressive lighter $\mathrm{Si}$ isotope compositions along the flow path, and assuming this is

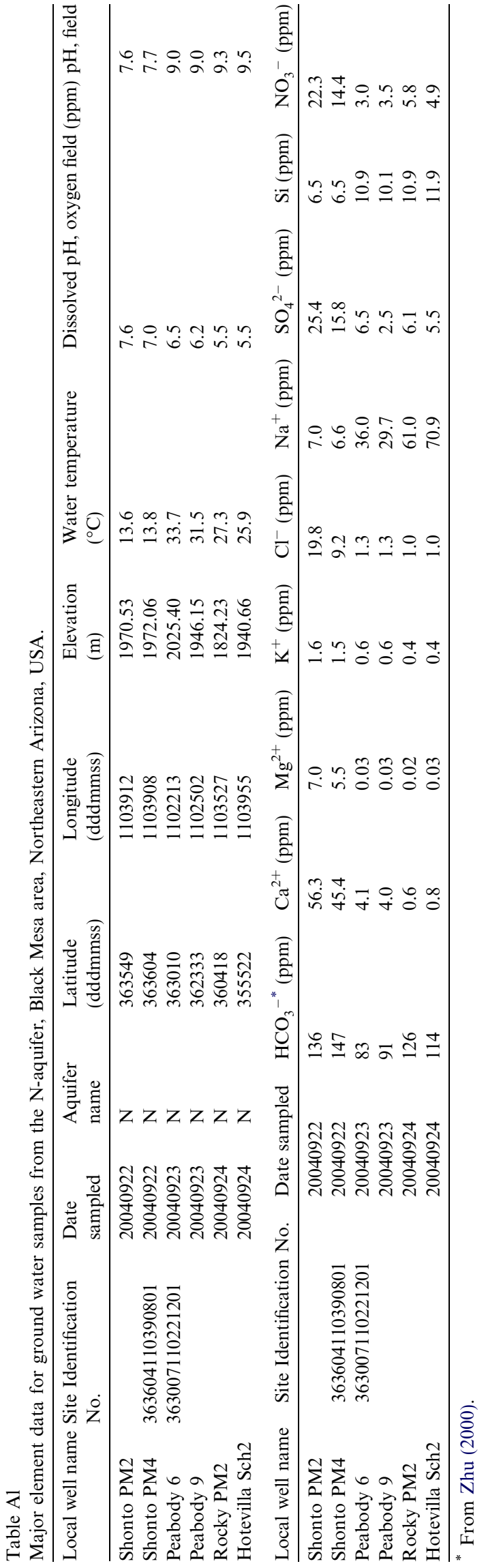


based on dissolution of different silcrete generations, it might thus mirror the palaeo-flow direction of the ancient groundwater.

\section{CONCLUSIONS}

We have analyzed stable silicon isotopes of groundwater together with detrital feldspars, clay coatings on
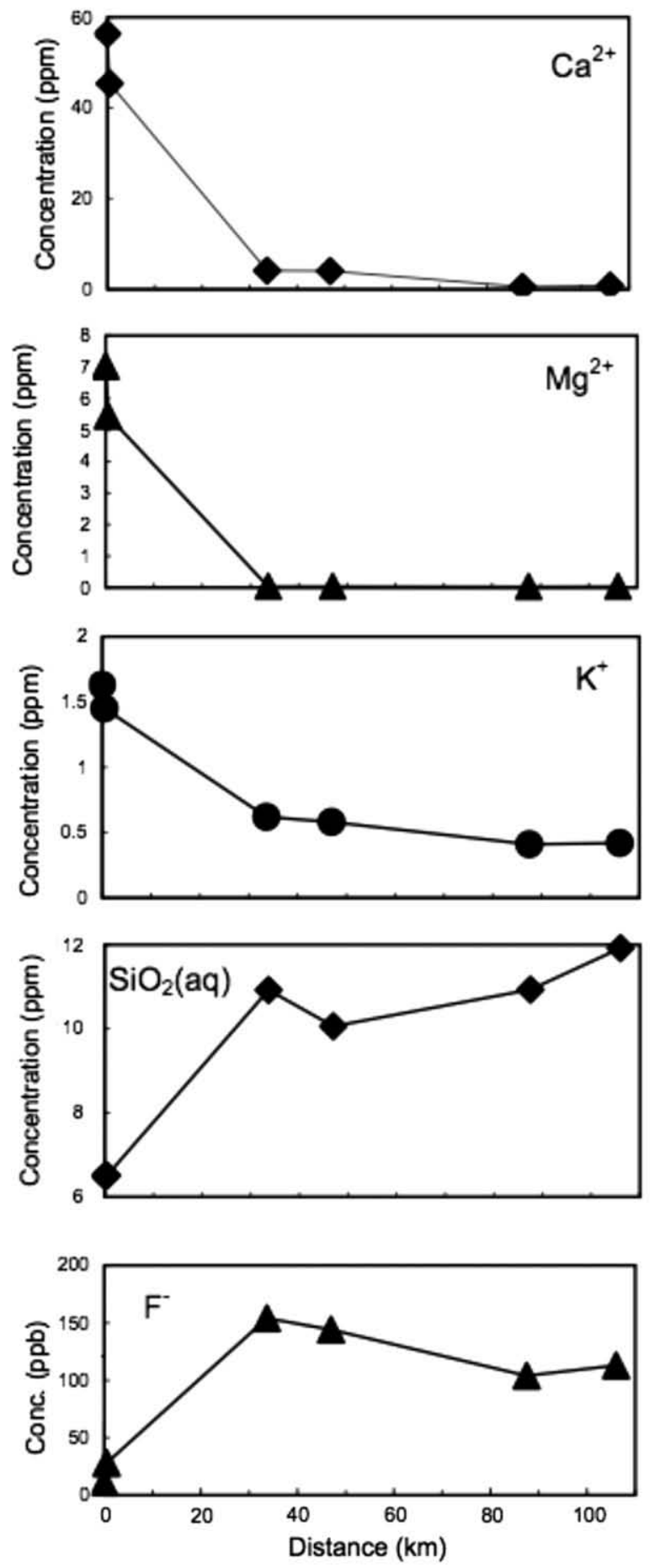

feldspar and quartz grains from the Navajo Sandstone aquifer at Black Mesa, Arizona, USA. The first analysis of groundwater samples revealed $\delta^{30} \mathrm{Si}$ values of dissolved silica spanning $\sim 2 \%$ along a $100 \mathrm{~km}$ transect, amply demonstrating the potential utility of stable $\mathrm{Si}$ isotopes in groundwater studies for deciphering weathering and diagenetic chemical reactions and cycling of $\mathrm{Si}$. Moreover, our data show that, as the groundwater flows
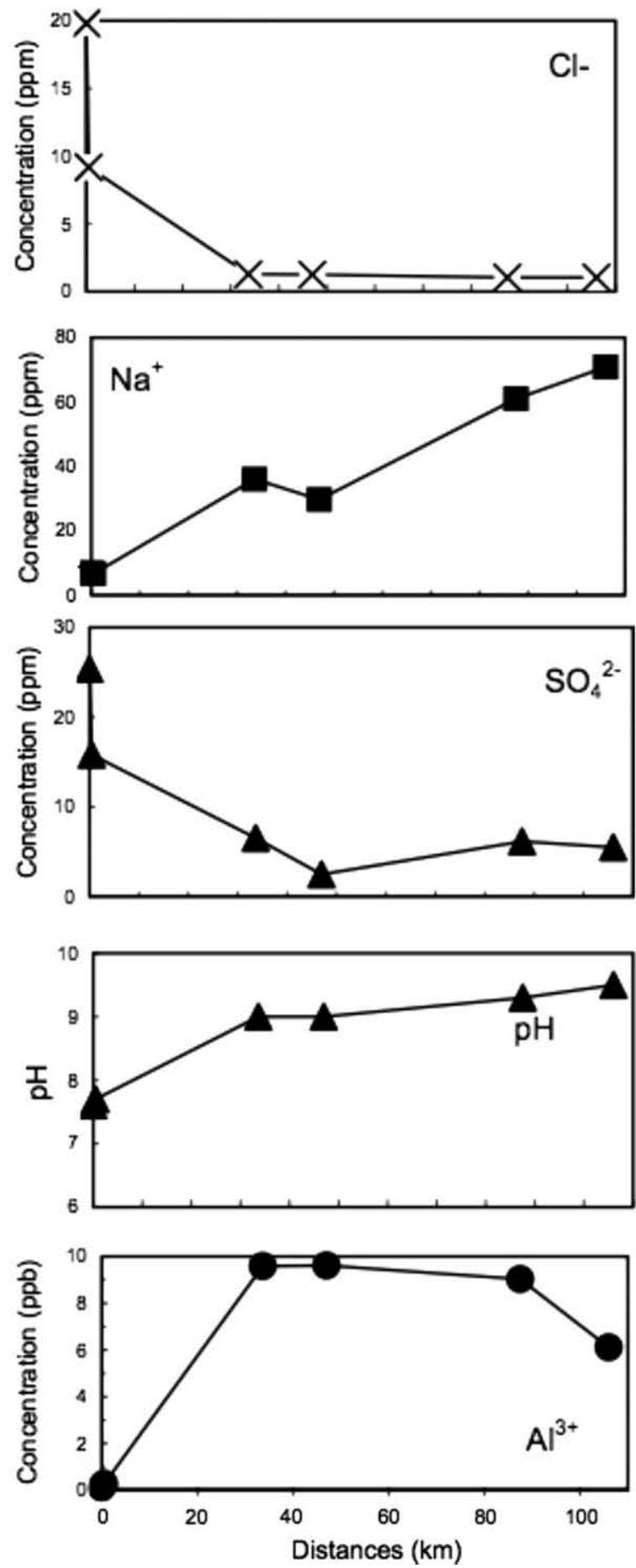

Fig. A1. Major chemistry evolution along the flow path in the N-aquifer, Black Mesa, Arizona. The locations of the wells are marked in Figs. 1 and 2. 
along the flow path, its $\mathrm{Si}$ isotope composition evolves towards negative $\delta^{30} \mathrm{Si}$ values, reaching as low as $-1.42 \%$. The negative values in groundwater require a source enriched in ${ }^{28} \mathrm{Si}$. At Black Mesa, we believe that the source of ${ }^{28} \mathrm{Si}$ enriched $\mathrm{Si}$ is partly secondary mineral coatings, but mainly low-temperature silcretes.

Our attempt to analyze co-existing primary and secondary silicate minerals and ambient fluids produced results that are consistent with the prevailing hypothesis of clay induced $\mathrm{Si}$ isotope fractionation in surficial systems. The detrital feldspars have $\delta^{30} \mathrm{Si}$ values $(-0.15 \%)$ similar to igneous rocks, the clay coatings are isotopically lighter by up to $0.4 \%$, and the groundwater in the actively weathering zone of $0.56 \%$.

Overall our study shows a more complex cycling of $\mathrm{Si}$ than previously realized as shown in our groundwater data along the $100 \mathrm{~km}$ transect. Stable Si isotopes unmasked reactions that eluded the studies of elemental concentrations alone. Clearly more studies of groundwater stable $\mathrm{Si}$ isotopes are needed.
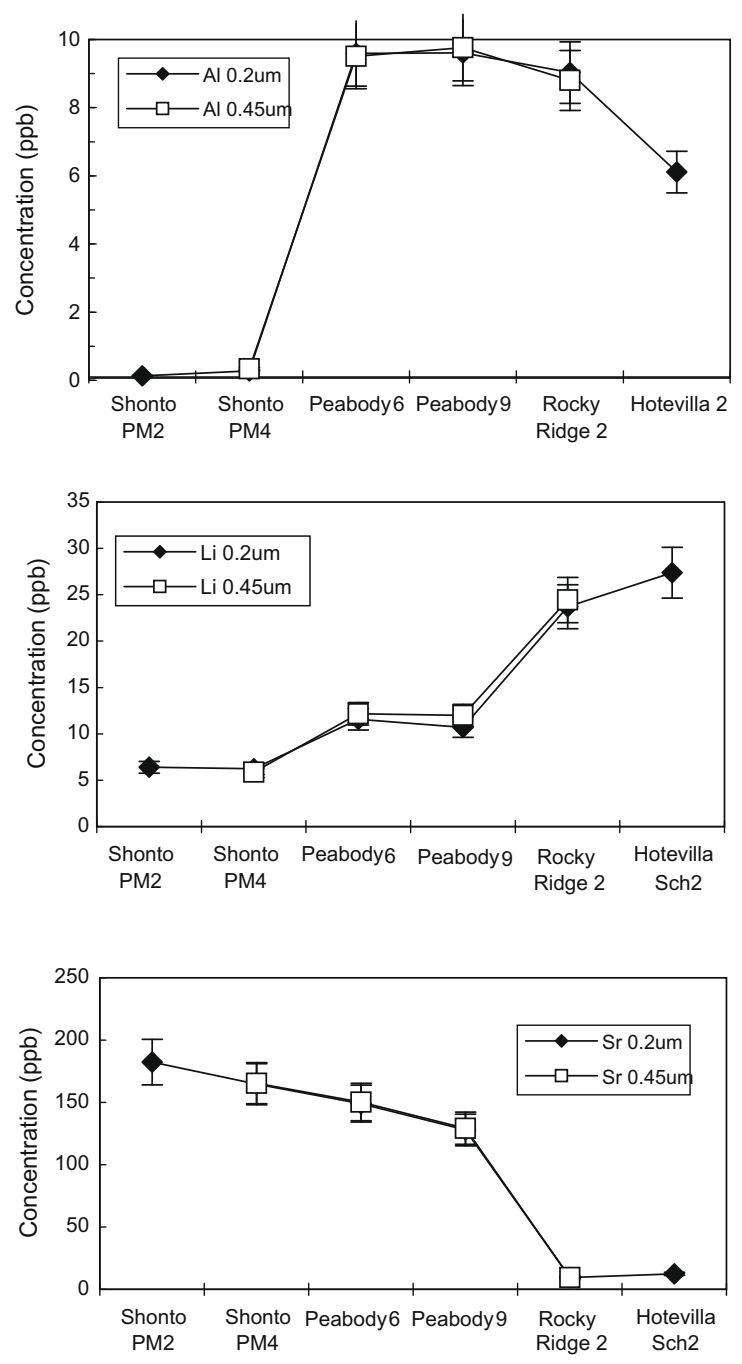

\section{ACKNOWLEDGMENTS}

This work is partly supported by the National Science Foundation under Award Nos. EAR0423971 and EAR0509775 to C.Z., the Swiss National Funds (No. 2000 20/101 78) and NERC to A.N.H. Any opinions, findings, and conclusions or recommendations expressed in this material, however, are those of the authors and do not necessarily reflect the views of any funding governments or any agency thereof. We want to thank Felix Oberli for maintaining the Nu1700, Nick Belshaw and Karla Newman for trouble shooting the NuPlasma in Oxford, Rick for ICP-MS analysis, and Margoit Truini and Arndt Schimmelmann for help with field sampling. We also would like to thank Matt Leybourne and two anonymous reviewer for important and insightful comments, and Karen Johannesson for helpful comments and editorial handling.

\section{APPENDIX A. HYDROCHEMISTRY DATA AND DISCUSSION}

To aid the interpretation of the $\mathrm{Si}$ isotope data, dissolved chemical constituents were also analyzed. The major element
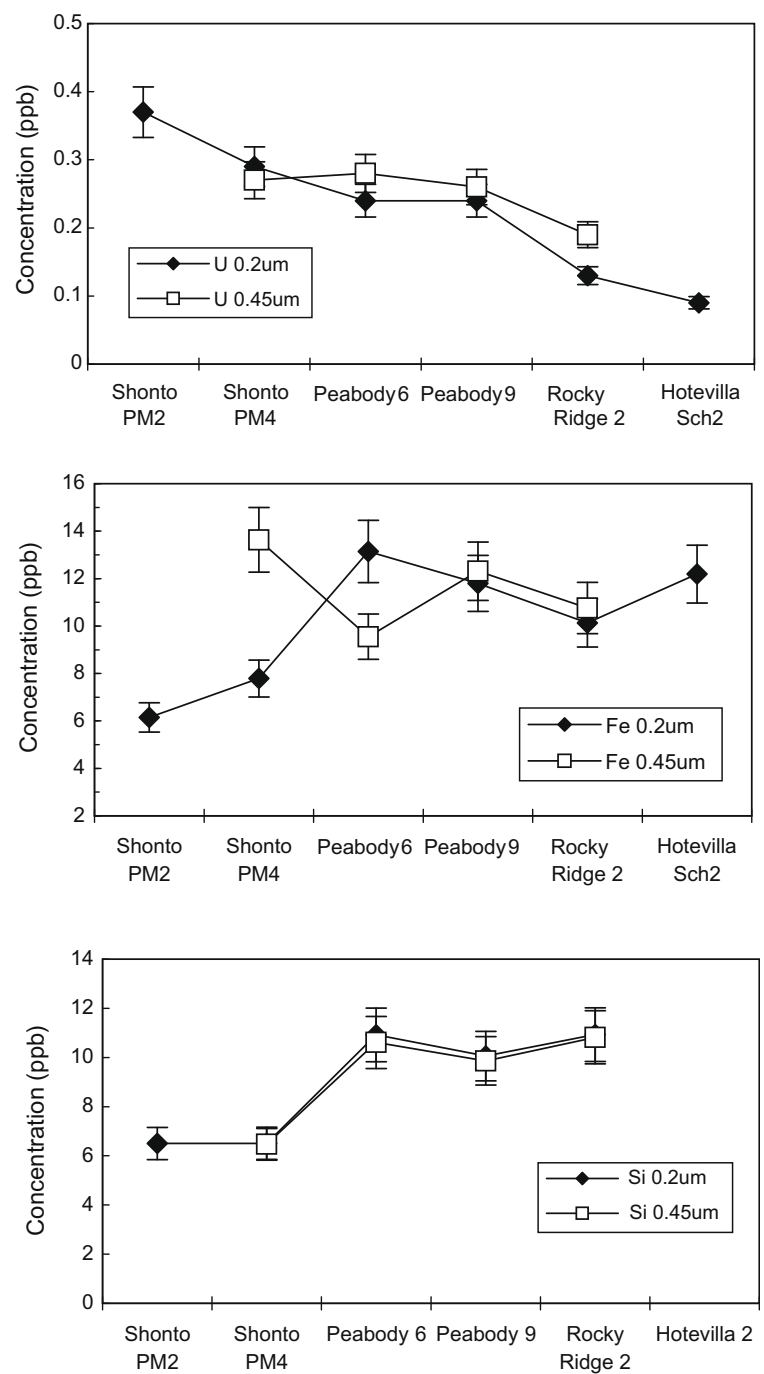

Fig. A2. Comparison of ion concentrations in samples using $0.2 \mu \mathrm{m}$ and $0.45 \mu \mathrm{m}$ filters. Error bars denote $10 \%$ uncertainties. Nav6 and Nav9 are well names equivalent to Peabody 6 and Peabody 9. 
data of the groundwater samples are listed in Table A1. The evolutionary path of groundwater geochemistry is generally clear in the Navajo Sandstone aquifer (Fig. A1) and is consistent with previous studies (Cooley et al., 1969; Wickham, 1992; Zhu, 2000). In the Shonto area, the groundwater is of the $\mathrm{Ca}^{2+}-\mathrm{Mg}^{2+}-\mathrm{HCO}_{3}{ }^{-}$type with a $\mathrm{pH}$ of $7.5-7.7$. Shortly after groundwater enters into the basin, $\mathrm{Ca}^{2+}$ and $\mathrm{Mg}^{2+}$ concentrations decrease sharply while $\mathrm{Na}^{+}$concentration increase proportionally, and the $\mathrm{pH}$ increases to 9-9.5.

To ensure that the measured $\mathrm{Si}$ isotopes of groundwater represent the dissolved silica, we sampled and analyzed groundwater using both $0.2 \mu \mathrm{m}$ and standard $0.45 \mu \mathrm{m}$ pore size filters. Aluminosilicate colloids commonly occur in natural waters. However, water samples that passed through $0.2 \mu \mathrm{m}$ and $0.45 \mu \mathrm{m}$ filters show negligible differences in $\mathrm{SiO}_{2}(\mathrm{aq})$ concentrations (Fig. A2). Uranium, strontium, and lithium also show comparable concentrations in water samples that passed through the two different filters (Fig. A2). However, iron concentrations show notable differences in wells Shonto PM4 and Peabody 6 although concentrations are comparable in other three wells.

The concern for possible aluminosilicate colloids in natural water samples also relates to the analysis of "truly dissolved" $\mathrm{Al}^{3+}$ and calculations of saturation indices for aluminosilicates in natural waters. Driscoll and Postek (1996) noted that "... because particulate minerals exhibit a continuous size distribution, no absolute distinction between dissolved and particulate forms can be made, and results show a strong dependence on filter size." However, the eolian Navajo Sandstone offers an excellent opportunity to determine the dissolved $\mathrm{Al}^{3+}$ concentrations. Water samples passed through $0.2 \mu \mathrm{m}$ and $0.45 \mu \mathrm{m}$ filters show negligible differences in $\mathrm{Al}^{3+}$ concentrations. Overall, these results using two different pore size filters suggest that
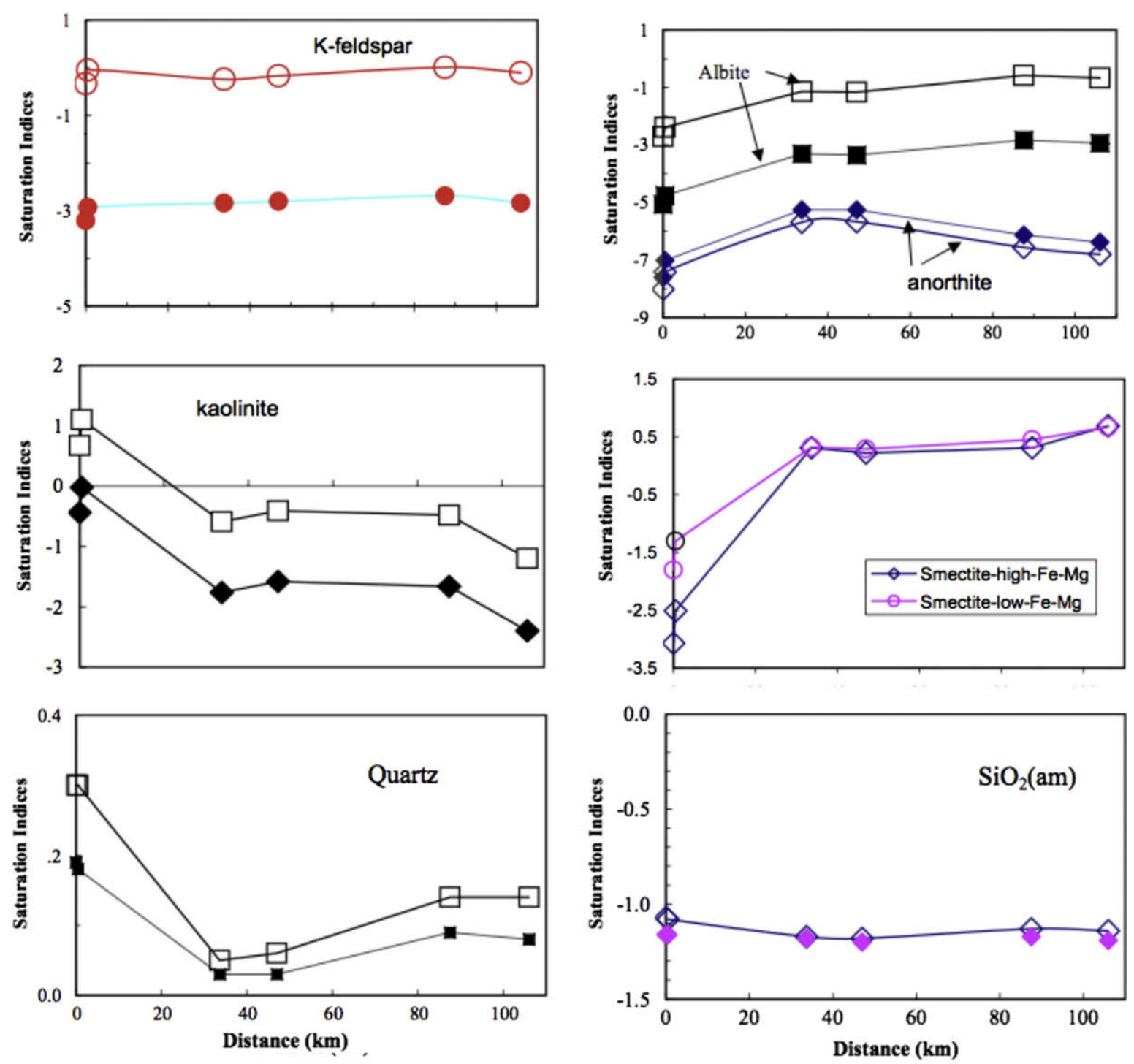

Fig. A3. Calculated saturation indices (SI) for relevant minerals. Open and solid symbols represent calculated with databases Phreeqc.dat and llnl.dat associated with the program PHREEQC, respectively. 
groundwater samples from the Navajo Sandstone do not contain colloids that are in the range of 0.2 and $0.45 \mu \mathrm{m}$, and the analyzed silica (and isotopes) and aluminum represent the dissolved portion of the elements.

Based on the major ion chemistry data, saturation states with respect to relevant minerals in groundwater samples were calculated. For all calculations, the standard states for the solids are defined as unit activity for pure solids at the temperature and pressure of interest. The standard state for water is the unit activity of pure water. For aqueous species other than $\mathrm{H}_{2} \mathrm{O}$, the standard state is the unit activity of the species in a hypothetical one molal ideal solution referenced to infinite dilution at the temperature and pressure of interest. Speciation and solubility calculations were aided with the computer code Phreeqc (Parkhurst and Appelo, 1999) or EQ3/6 (Wolery, 1979). Activity coefficients for the charged aqueous species were calculated from the Davis equation.

While we demonstrated that colloids are not a concern for $\mathrm{Si}$ and $\mathrm{Al}$ analyses used in saturation indices calculations, there are considerable differences in standard thermodynamic properties for minerals and aqueous species in various compilations (e.g. Helgeson et al., 1978; Nordstrom et al., 1990), which appears to give quite different SI values (Fig. A3). However, it can be deduced that groundwater along the entire flow path is grossly undersaturated with respect to albite and anorthite, and grossly or slightly undersaturated with respect to K-feldspar (Fig. A3). Upstream in the recharge area (Shonto PM2 and PM4), the groundwater is supersaturated with respect to kaolinite. Moving down-
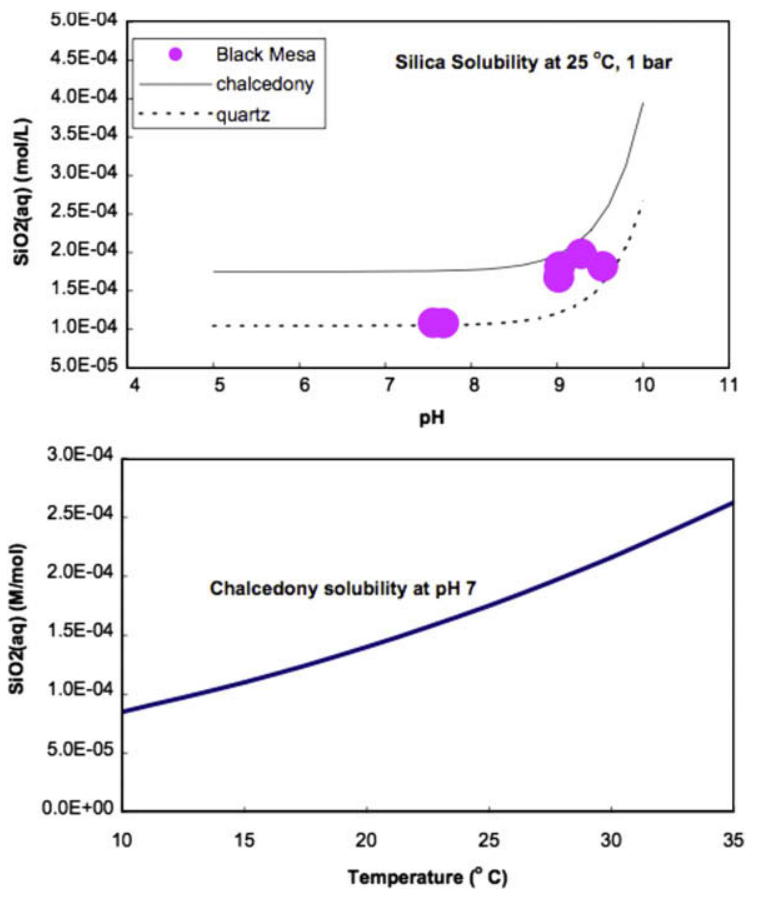

Fig. A4. Calculated silica solubility as a function of $\mathrm{pH}$ and temperature. Amorphous silica solubilities are much higher and are off the chart. Thermodynamic properties were from (Ball and Nordstrom, 1991). stream, groundwater is undersaturated with respect to kaolinite near the Peabody wells to the Hotevilla wells.

Groundwater is supersaturated with respect to quartz, but undersaturated with respect to amorphous quartz. Saturation index values for smectite is difficult to assess because of its complex structures and chemistry and the lack of thermodynamic properties and solid solution models to account for the chemical and structural variations. For the smectites in the databases (Smectite-high-Fe-Mg, $\mathrm{Ca}_{.025 .1} \mathrm{~K}_{2 .} \mathrm{Fe}_{.5} \mathrm{Fe}_{.2} \mathrm{Mg}_{1.15} \mathrm{Al}_{1.25} \mathrm{Si}_{3.5} \mathrm{H}_{2} \mathrm{O}_{12}$, Smectite-low$\mathrm{Fe}-\mathrm{Mg}, \mathrm{Ca}_{.02} \mathrm{Na}_{.15} \mathrm{~K}_{.2} \mathrm{Fe}_{.29} \mathrm{Fe}_{.16} \mathrm{Mg}_{.9} \mathrm{Al}_{1 \cdot 25} \mathrm{Si}_{3.75} \mathrm{H}_{2} \mathrm{O}_{12}$ ), we see undersaturation in the recharge zone, but supersaturated in the down stream area (Fig. A3).

Silica solubilities are a strong function of $\mathrm{pH}$ and temperature. Fig. A4 shows the calculated solubilities for quartz and chalcedony for the range of $\mathrm{pH}$ and temperatures in our samples. The variation of solubilities of silica with $\mathrm{pH}$ and temperature is an important part of the Si evolution along the flow path.

\section{REFERENCES}

Abraham K., Opfergelt S., Fripiat F., Cavagna A.-J., de Jong J. T. M., Foley S., Andre L. and Cardinal D. (2008) D30Si and d29Si determination on BHVO-1 and BHVO-2 reference materials with a new configuration on a Nu Plasma Multi Collector ICPMS. Geostand. Geoanal. Res. 32, 193-202.

Alleman L. Y., Cardinal D., Cocquyt C., Plisnier P. D., Descy J. P., Kimirei I., Sinyinza D. and Andre L. (2005) Silicon isotopic fractionation in Lake Tanganyika and its main tributaries. $J$. Great Lakes Res. 31, 509-519.

Allenby R. J. (1954) Determination of the isotopic ratios of silicon in rocks. Geochim. Cosmochim. Acta 5, 40-48.

Ball J. W. and Nordstrom, D. K. (1991) User's manual for WATEQ4F, with revised thermodynamic data base and test cases for calculating speciation of major, trace, and redox elements in natural waters. U.S. Geological Survey Open-File Report.

Basile-Doelsch I., Meunier J. D. and Parron C. (2005) Another continental pool in the terrestrial silicon cycle. Nature 433, 399402.

Beucher C. P., Brzezinski M. A. and Jones J. L. (2008) Sources and biological fractionation of Silicon isotopes in the Eastern Equatorial Pacific. Geochim. Cosmochim. Acta 72, 3063-3073.

Bromley M. (1992) Topographic inversion of early interdune deposits, Navajo Sandstone (Lower Jurassic), Colorado Plateau, USA. Sedimentary Geol. 80, 1-25.

Brown J. G. and Eychaner J. H. (1988) Simulation of five groundwater withdrawal projections for the Black Mesa area, Navajo and Hopi Indian Reservations, Arizona. U.S. Geological Survey. p. 51.

Burnett W. C., Gullaya W., Taniguchi M., Dulaiova H., Sojisuporn P., Rungsupa S. and Ishitobi T. (2007) Groundwaterderived nutrient inputs to the Upper Gulf of Thailand. Cont. Shelf Res. 27, 176-190.

Cardinal D., Alleman L. Y., Dehairs F., Savoye N., Trull T. W. and André L. (2005) Relevance of silicon isotopes to Si-nutrient utilization and Si-source assessment in Antarctic waters. Glob Biogeochem. Cycl. 17 (GB2007), doi:10.1029/2004GB002364.

Cooley M. E., Harshbarger J. W., Akers J. P. and W.F. H. (1969) Regional hydrogeology of the Navajo and Hopi Indian Reservations, Arizona, New Mexico, and Utah. U.S. Geological Survey Professional Paper 521-A, p. 61. 
De La Rocha C. L. (2003) Silicon isotope fractionation by marine sponges and the reconstruction of the silicon isotope composition of ancient deep water. Geology 31, 423-426.

De La Rocha C. L., Breszinski M. A. and DeNiro M. J. (1997) Fractionation of silicon isotopes by marine diatoms during biogenic silica formation. Geochim. Cosmochim. Acta 61, 50515056.

De La Rocha C. L., Brezinski M. A. and DeNiro M. J. (2000) A first look at the distribution of the stable isotopes of silicon in natural waters. Geochim. Cosmochim. Acta 64, 2467-2477.

Delstanche S., Opfergelt S., Cardinal D., Elsass F., Andre L. and Delvaux B. (2009) Silicon isotopic fractionation during adsorption of aqueous monosilisic acid onto iron oxide. Geochim. Cosmochim. Acta 73, 923-934.

Ding T. (1996) Silicon Isotope Geochemistry. Geological Publishing House, Beijing, pp. 125.

Ding T., Ma G. R., Shui M. X., Wan D. F. and Li R. H. (2005) Silicon isotope study on rice plants from the Zhejiang province, China. Chem. Geol. 218(1-2), 41-50.

Ding T. P., Zhou J. X., Wan D. F., Chen Z. Y., Wang C. Y. and Zhang F. (2008) Silicon isotope fractionation in bamboo and its significance to the biogeochemical cycle of silicon. Geochim. Cosmochim. Acta 72(5), 1381-1395.

Ding T., Wan D., Wang C. and Zhang F. (2004) Silicon isotope compositions of dissolved silicon and suspended matter in the Yangtze River, China. Geochim. Cosmochim. Acta 68, 205-216.

Douthitt C. B. (1982) The geochemistry of the stable isotopes of silicon. Geochim. Cosmochim. Acta 46, 1449-1458.

Driscoll C. T. and Postek K. M. (1996) The chemistry of aluminum in natural waters. In The Environmental Chemistry of Aluminum (ed. G. Sposito). CRC Press LLC, pp. 363-418.

Dulaney A. R. (1989) The geochemistry of the N-aquifer system, Navajo and Hopi Indian Reservations, Northeastern Arizona. Master thesis, Northern Arizona University. 209p.

Eychaner J. H. (1983) Geohydrology and effects of water use in the Black Mesa area, Navajo and Hopi Indian Reservations, Arizona. U.S. Geological Survey Water Supply Paper 2201. p. 26.

Georg R. B. (2006) Geochemistry of Stable Silicon Isotopes Measured by High-Resolution Multi-Collector Inductively-Coupled-Plasma Mass-Spectrometry (HR-MC-ICP-MS). Swiss Federal Institute of Technology (ETH).

Georg R. B., Halliday A. N., Schauble E. A. and Reynolds B. C. (2007a) Silicon in the Earth's Core. Nature 447, $1102-1106$

Georg R. B., Reynolds B. C., Burton K. W. and Halliday A. N. (2007b) Silicon isotope variations accompanying basalt weathering on Iceland. Earth Planet. Sci. Lett. 261, 476-490.

Georg R. B., Reynolds B. C., Frank M. and Halliday A. N. (2006a) Mechanisms controlling the silicon isotopic compositions of river waters. Earth Planet. Sci. Lett. 249, 290-306.

Georg R. B., Reynolds B. C., Frank M. and Halliday A. N. (2006b) New sample preparation techniques for the precise determination of the $\mathrm{Si}$ isotope composition of natural samples using MC-ICP-MS. Chem. Geol. 235, 95-104.

Georg R. B., Reynolds B. C., Halliday A. N. and Zhu C. (2005) Fractionation of stable $\mathrm{Si}$ isotopes during in-situ dissolution of feldspars and formation of secondary clay minerals. EOS Trans AGU Fall Meet. Suppl. 86 (52), Abstract.

Harshbarger J. W., Repenning C. A. and Irwin J. H. (1957) Stratigraphy of the Uppermost Triassic and the Jurassic Rocks of the Navajo Country. U.S. Geological Survey Professional Paper 291. p. 71.

Helgeson H. C., Delany J. M., Nesbitt H. W. and Bird D. K. (1978) Summary and critique of the thermodynamic properties of rock forming minerals. Am. J. Sci. 278A, 569-592.
Kim G., Ryu J. W., Yang H. S. and Yun S. T. (2005) Submarine groundwater discharge (SGD) into the Yellow Sea revealed by 228Ra and 226Ra isotopes: implications for global silicate fluxes. Earth Planet. Sci. Lett. 237, 156-166.

Matlack K. S., Houseknecht D. W. and Applin K. R. (1989) Emplacement of clay into sand clay by infiltration. J. Sediment. Petrol. 59, 77-87.

Moore W. S., Sarmiento J. L. and Key R. M. (2008) Submarine groundwater discharge revealed by $228 \mathrm{Ra}$ distribution in the upper Atlantic Ocean. Nat. Geosci. 1, 309-311.

Mucke A. (1994) Part I. Postdiagenetic ferruginization of sedimentary rocks (sandstones, oolitic ironstones, kaolins and bauxites) - including a comparative study of the reddening of the red beds. In Diagnesis, IV, Vol. Developments in Sedimentology (eds. K. H. Wolf and G. V. Chilingarian). Elsevier, pp. 361-423.

Niencheski L. F. H. (2007) Submarine groundwater discharge of nutrients to the ocean along a coastal lagoon barrier, Southern Brazil. Mar. Chem. 106, 546-561.

Nordstrom D. K., Plummer L. N., Langmuir D., Busenberg E., May H. M., Jones B. and Parkhurst D. L. (1990) Revised chemical equilibrium data for major water-mineral reactions and their limitations. In Chemical Modeling of Aqueous Systems II (eds. D. C. Bassett and R. L. Melchior). American Chemical Society, pp. $398-413$.

Opfergelt S., Cardinal D., Henriet C., Andre L. and Delvaux B. (2006a) Silicon isotope fractionation between plant parts in banana: in situ vs in vitro. J. Geochem. Expl. 88, 224-227.

Opfergelt S., Cardinal D., Henriet C., Draye X., Andre L. and Delvaux B. (2006b) Silicon isotope fractionation by banana (Musa spp.) grown in a continuous nutrient flow device. Plant Soil 285, 333-345.

Parkhurst D. L. and Appelo C. A. J., 1999. User's guide to PHREEQC (Version2) - a computer program for speciation, batch-reaction, one-dimensional transport and inverse geochemical calculations.

Reynolds B. C., Aggarwal J., Brzezinski M. A., Cardinal D., Engström E., Georg R. B., Land M., Leng M., Opfergelt S. and Vroon P. Z. (2007) An inter-laboratory calibration of Si isotope reference materials. J. Anal. Atomic Spectrosc. 22, 561-568.

Reynolds B. C., Frank M. and Halliday A. N. (2006) Silicon isotope fractionation during nutrient utilization in the North Pacific. Earth Planet. Sci. Lett. 244, 431-443.

Reynolds J. H. and Verhoogen J. (1953) Natural variations in the isotopic constitution of silicon. Geochim. Cosmochim. Acta 3, 224-234.

Schwartz F. W. and Zhang H. (2002) Fundamentals of Groundwater. Wiley, pp. 592.

Varela D. E., Pride C. J. and Brzezinski M. A. (2004) Biological fractionation of silicon isotopes in Southern Ocean surface waters. Glob. Biochem. Cycl. 18, 1-8, GB1047.

Wickham M. (1992) The geochemistry of surface water and groundwater interactions for selected Black Mesa drainages, Little Colorado river basin, Arizona. Master Thesis, The University of Arizona.

Wolery T. J. (1979) Calculation of chemical equilibrium between aqueous solutions and minerals. In The EQ3/6 Software Package. URCL-52658. Livermore, Calif., Univ. California, Lawrence Livermore Laboratory. p. 41.

Zhu C. (2000) Estimate of recharge from radiocarbon dating of groundwater ages and numerical flow and transport modeling. Water Resour. Res. 36(9), 2607-2620.

Zhu C. (2005) In situ feldspar dissolution rates in an aquifer. Geochim. Cosmochim. Acta 69(6), 1435-1453.

Zhu C., Veblen D. R., Blum A. E. and Chipera S. J. (2006) Naturally weathered feldspar surfaces in the Navajo Sandstone 
aquifer, Black Mesa, Arizona: Electron microscopic characterization. Geochim. Cosmochim. Acta 70(18), 4600-4616.

Ziegler K., Chadwick O. A., Brzezinski M. A. and Kelly E. F. (2005a) Natural variations of $\delta^{30} \mathrm{Si}$ ratios during progressive basalt weathering, Hawaiian Islands. Geochim. Cosmochim. Acta 69(19), 4597-4610.
Ziegler K., Chadwick O. A., White A. F. and Brzezinski M. A. (2005b) $\delta^{30} \mathrm{Si}$ systematics in a granitic saprolite, Puerto Rico. Geology 33(10), 817-820.

Associate editor: Karen Johannesson 